\title{
To What Extent are Stock Returns Driven by Mean and Volatility Spillover Effects? - Evidence from Eight European Stock Markets ${ }^{1}$
}

\begin{abstract}
Abdulla Alikhanov ${ }^{2}$
Abstract: The paper investigates mean and volatility spillover effects from the U.S and EU stock markets as well as oil price market into national stock markets of eight European countries. The study finds strong indication of volatility spillover effects from the US-global, EU-regional, and the world factor oil towards individual stock markets. While both mean and volatility spillover transmissions from the US are found to be significant, EU mean spillover effects are negligible. To evaluate the magnitude of volatility spillovers, the variance ratios are also computed and the results draw to attention that the individual emerging countries' stock returns are mostly influenced by the U.S volatility spillovers rather than EU or oil markets. Additionally, examination of only global and regional stock markets spillover transmissions into European stock markets also confirms the dominating presence of the U.S spillover transmissions. Furthermore, I also implement asymmetric tests on stock returns of eight markets. The stock market returns of Hungary, Poland, Russia and the Ukraine are found to respond asymmetrically to negative and positive shocks in the US stock returns. The weak evidence of asymmetric effects with respect to oil market shocks is found only in the case of Russia and the quantified variance ratios indicate that presence of oil market shocks are relatively higher for Russia. Moreover, a model with dummy variable confirms the effect of European Union enlargement on stock returns only for Romania. Finally, a conditional model suggests that the spillover effects are partially explained by instrumental macroeconomic variables, out of which exchange rate fluctuations play the key role in explaining the spillover parameters rather than total trade to GDP ratios in most investigated countries.
\end{abstract}

Key words: Stock markets, the U.S, E.U, volatility spillovers, emerging markets, mean, oil price, exchange rates, asymmetric effects.

JEL Classification: C26, C51, G15

\section{Introduction}

Over the last decades, financial markets have experienced dramatic expansion and interaction with one another. Higher liberalization of economies, globalization and interrelated synchronization of financial markets have influenced bilateral movements

\footnotetext{
${ }^{1}$ The author would like to thank Frederik Lundtofte and Lu Liu for helpful comments and suggestions.

2 Lund University, Department of Economics, P.O. Box 7082 S-220 07 Lund, Sweden: abdulla.alikhan@gmail.com
} 
of equity markets. As the result of globalization and integration and growing technological advances in financial markets, innovations and shocks in dominant equity as well as commodity markets are very likely to influence stock returns of emerging markets. Especially for investors, the behavior and sources of market volatility are of paramount importance for realization of hedging strategies and international asset diversification decisions on global financial markets. Additionally, the diversifications of portfolios of assets are also subject to interlinkages among capital markets. Hence, the understanding and investigation of this phenomenon is also very crucial for policy makers.

On the other hand, interrelated development of stock markets across developed and developing countries has created good opportunities for international investors to invest in stock markets of emerging economies. Needless to say, the financial markets of the emerging and developing economies have different characteristics compared to those of developed countries. For instance, an empirical study by Bekaert and Harvey (1995) on highly emerging markets which uses data of International Finance Corporation (IFC) finds out that compared to advanced markets, emerging markets are characterized by relatively high returns and low correlation. Emerging stock markets seem to be very appealing for investing since they provide higher expected returns. Besides higher sample expected returns, distinguishing characteristics of emerging markets are, among other things, recognized relatively low correlations with mature capital markets and higher volatility (Harvey 1995). Thus, these differences make a an empirical investigation of emerging stock markets very appealing, and it isinteresting and valuable to examine stock returns of European emerging and developing markets within a mean and volatility spillovers framework.

The purpose of this paper is to examine the mean and volatility spillovers effects from a global factor US (GF US) ${ }^{3}$ stock market, regional factor Europe (RF EU) stock market and as the world factor oil price (WF Oil) changes on the eight European emerging and developing countries from September 2000 until March 2012. The countries examined are: Croatia, Czech Republic, Hungary, Poland, Romania, Russia, Turkey, and the Ukraine. The mean and volatility spillover effects across financial markets are explored by applying the GJR-GARCH model introduced by Glosten, Jagannathan and Runkle in 1993. Eventually, the calculated variance ratios will allow us to quantitatively analyze the proportion of volatility spillovers from various sources. Additionally, by excluding the oil spillover effects, the paper also examines the size and effect of spillover effects from two markets only: Europe and the US.

Although the spillover models are explored by using the GJR-GARCH model, the asymmetric tests on stock returns of individual countries will provide for a more comprehensive investigation of asymmetric existence with respect to any spillover intensities. Additionally, the paper includes oil price shocks as a world factor to examine possible spillover effects on stock returns. Moreover, the paper applies macroeconomic information instruments through conditional spillover model. Finally, the sensitivity analysis and EU enlargement effect from this study aim to respectively,

${ }^{3}$ Throughout the paper, the terms "Global Factor US", "Regional Factor EU" as well as "World Factor Oil" are respectively coined with "GF US", "RF EU" and "WF OIL" 
contribute an estimation framework and useful information about future expectations for investors investing other EU candidate stock markets. More specifically, this study aims to address the following research questions:

1. How do mean and volatility spillover effects of the US, the EU and the oil market, as a world factor, drive stock returns in European emerging and developing markets?

2. Which spillover effect has the possibility of having highest magnitude effect on the selected eight national European stock markets?

3. Does the EU enlargement matter for spillover effects on stock returns?

4. How well are the macroeconomic instruments able to explain global US and regional EU spillover effects?

\section{Literature review}

One of the pioneering papers in this field, which investigates volatility spillover effects of twenty emerging markets in the world is studied by Bekaert and Harvey (1997) who conclude that global factors drive more volatility effects in the fully integrated markets, however, in the segmented markets volatility seems to be caused mostly by local factors. Their study also draws attention to the fact that although volatility appears to be different in various emerging markets, more liberalized open economies tend to possess lower volatiles, and capital market liberalization process is the one of the pronounced driving factor in significant decrease in volatilities.

Furthermore, Rockinger and Urga (2001) explore effects of London and Frankfurt stock exchange markets on Central European stock markets over the 1994-1997 period. By applying a similar method proposed by Bekaert and Harvey (1997), they revealed that although both markets drive significant volatility spillover effects, the effects from UK stock market tend to be more substantial than those of German stock markets. Another research by Scheicher (2001) investigates the stock markets of Central and Eastern European (CEE) countries, namely, Czech, Hungary, and Poland in the light of regional and global financial market interdependences. Author's study concludes that equity markets are influenced by regional and global spillover effects. On the contrary, the volatility spillovers seem to be driven by regional factors mostly. On the other hand, Gilmore and McManus (2002) examine short and long run integration and bilateral relationships between the US and individual CEE stock markets, and find out that indication of possible interaction is negligible. Applying cointegration tests the empirical study by Égert and Koubaa (2004) based on GARCH model indicates that CEE countries are characterized by a higher volatility and more asymmetry than G-7 countries. Moreover, the interactions between three CEE states and developed markets such as Germany and the US are explored by Syriopoulos (2007). The author finds long run interactions between developed countries and CEE states. In the short run, however, US stock market returns impose more dominant effects than those from Germany. 
Another research study by Kasman and Torun (2009) investigates the presence of dual long memory approach proposed by Teyssiere (1997). Their findings show significant evidence of long memory in time varying variance and mean for CEE stock markets applying fractionally integrated autoregressive GARCH model. Kocenda and Hanousek (2010) use highly frequent intraday data to examine spillovers and macroeconomic news effects from global factor US and regional factor Germany into Czech Republic, Hungary, and Poland. The authors consider the Frankfurt stock exchange as a regional factor. They find out that although both of the markets drive strong volatility spillover transmissions, spillover effects induced by regional Frankfurt Stock is higher than that of the New York stock exchange market. Along the way, one of the extensive empirical studies introduced by Beine, Caporale, and Spagnolo (2010) investigates equity markets of 41 developing countries across the world, and finds out that in most of the countries equity returns are influenced regional and global spillover effects. Using VAR-MGARCH $(1,1)$ model, authors also conclude that Asian and Latin America countries are more exposed both to return and volatility spillovers, while in emerging European countries volatility spillovers are main statistical driven stock markets. In addition to that, if the global spillover effects are dominating in emerging Asian financial markets, regional spillovers appear to be more pronounced in Latin America and developing European countries.

Last but not least, Gilmoure et. al., (2006), analyses co-movements of CEE and developed EU stock market returns. Relying on static and dynamic methods, they report that co-movements between financial markets have not altered much after EU membership. On the other hand, behavior of stock returns of "new" EU member countries was explored by Dvořák and Podpiera (2006), who conclude that some Baltic and CEE countries' accession to EU is followed by higher stock market returns. Similar results are observed in earlier studies for different markets by Henry (2000), Bekaert and Harvey (2000). Common result is that stock market indexes have been significantly increased in response to financial market integration.

In summary, we have seen that most empirical studies have focused on developed markets both across the World and in Europe. After EU enlargement process, some more new empirical studies have been carried out on Central and Eastern European countries (CEECs) in recent years. Still, empirical examination of stock markets of other emerging countries such as Croatia, Russia, the Ukraine and Turkey are underresearched, which gives cause to the need of further investigation and a deeper analysis (e.g. Multivariate analysis) which are still being executed.

\section{Data description}

The data used in this paper were obtained from DataStream International. The raw data consists of stock indexes of US, aggregate index of EMU countries, crude oil spot prices and eight stock indexes of eight European countries such as Croatia, Czech Republic, Hungary, Poland, Romania, Russia, the Ukraine, and Turkey. Sample period of employed data stock indexes is weekly based and spans from September 1, 2000, to March, 30, 2012 (Figure 1). In total, the data span includes 604 observations.All indexes used in the study are in US dollar and were obtained directly from Thomson International. 
The broad market index S\&P 500 represents the global index, whilst MSCI EU reflects regional market index, and both of them have been considered to be the so called "broad based indexes" in US and European developed markets respectively. In addition, MSCI EU represents all European developed markets.

Figure 1: Indexes and returns
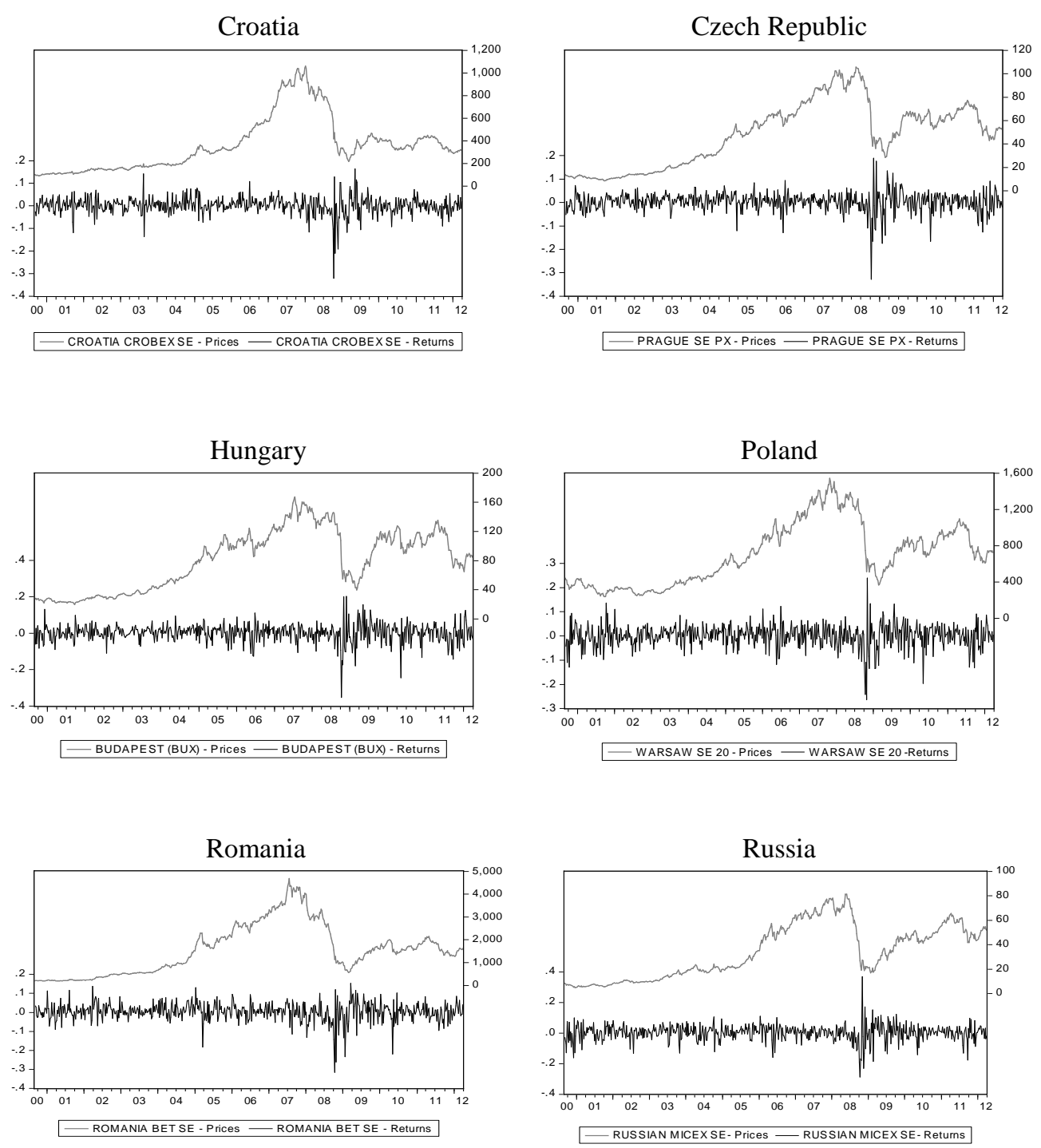

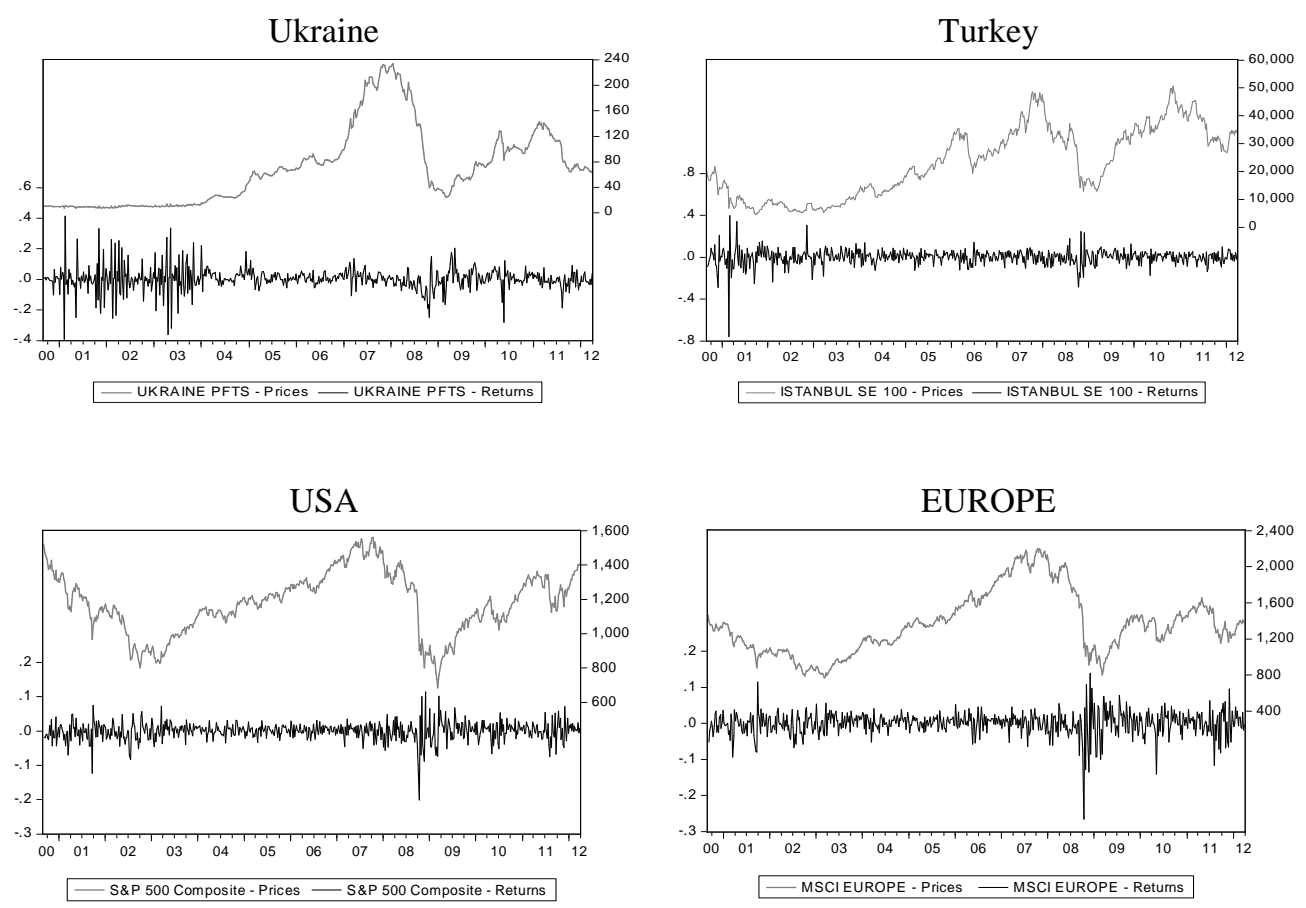

Source: Thomoson Financial Database, 2012

Being captured is $90 \%$ of the capitalization of large and liquid securities. According to Bloomberg, (2012), MSCI index is consists of large and liquid securities, and captures $90 \%$ of the capitalization of the broader benchmark. All the indexes are transformed to returns by taking the difference between $\log$ of indexes at time $t$, and the log of their own value at time $t-1$.

The data used for crude oil price is also weekly based. Moreover, macroeconomic variables employed in this study, such as exchange rate changes of each currency against Euro and USD, GDP of individual European emerging countries and total trade between US, EMU countries, and each of the local country is obtained quarterly. The data for crude prices are extracted from EAI and the macro variables are obtained both from DataStream and national statistics authorities of each European country.

Descriptive statistics for each of the indexes of different markets are provided in Table 1. All individual countries mean returns are higher than US and European aggregate returns. 
Table 1: Summary statistics of the weekly stock market returns, 09-2000-03-2012

\begin{tabular}{|c|c|c|c|c|c|c|c|c|c|c|}
\hline & $\begin{array}{l}\text { N. of } \\
\text { OBS }\end{array}$ & Mean & Median & Max. & Min. & $\begin{array}{l}\text { Std. } \\
\text { dev. }\end{array}$ & Skewness & Kurtosi & $\begin{array}{c}\text { Jarque- } \\
\text { Bera Test }\end{array}$ & $\mathrm{P}$-value \\
\hline Croatia & 604 & 0,192 & 0,296 & 16,338 & $-32,000$ & 3,880 & $-1,301$ & 13,732 & 3069,26 & 0.00 \\
\hline $\begin{array}{l}\text { Czech } \\
\text { Rep. }\end{array}$ & 604 & 0,213 & 0,614 & 18,936 & $-32,780$ & 4,120 & $-1,244$ & 12,201 & 2286,56 & 0.00 \\
\hline Hungary & 604 & 0,218 & 0,629 & 20,158 & $-35,320$ & 4,480 & $-0,914$ & 9,106 & 1022,98 & 0.00 \\
\hline Poland & 604 & 0,219 & 0,497 & 24,003 & $-26,340$ & 4,770 & $-0,646$ & 6,799 & 405,47 & 0.00 \\
\hline Romania & 604 & 0,342 & 0,474 & 15,310 & $-31,590$ & 4,760 & $-1,224$ & 9,492 & 1211,87 & 0.00 \\
\hline Russia & 604 & 0,308 & 0,759 & 37,055 & $-28,720$ & 5,420 & $-0,457$ & 8,891 & 892,71 & 0.00 \\
\hline Ukraine & 604 & 0,298 & 0,199 & 41,360 & $-39,163$ & 7,610 & $-0,030$ & 9,397 & 1030,10 & 0.00 \\
\hline Turkey & 604 & 0,093 & 0,642 & 39,680 & $-75,781$ & 7,470 & $-1,623$ & 23,072 & 10404,94 & 0.00 \\
\hline EMU & 604 & $-0,061$ & 0,282 & 13,020 & $-27,340$ & 3,780 & $-0,986$ & 8,885 & 969,67 & 0.00 \\
\hline USA & 604 & $-0,013$ & 11,350 & 11,350 & $-20,084$ & 2,700 & $-0,813$ & 9,737 & 1208,99 & 0.00 \\
\hline
\end{tabular}

During the sample period, the highest returns in USD are characterized in Romania and Russia, respectively, $0.342 \%$ and $0.308 \%$. Turkey has a lowest mean return of $0.093 \%$, followed by Croatia $0.192 \%$. Moreover, the volatility of stock markets is much higher for the Ukraine, Turkey and Russia with 7.610\%, $7.470 \%$ and $5.420 \%$ standard deviations, respectively. It should be mentioned that mean returns and standard deviations for three Central Eastern European (CEE) emerging economies, namely the Czech Republic, Hungary and Poland are very close to each other. Although the mean returns of stock markets are higher for developing countries, those markets are characterized with higher volatilities.

\section{Empirical model}

The generalized autoregressive conditional heteroskedasticity (GARCH) process is recognized model for analysis of volatility and return spillovers amongst international financial markets. The main econometric specification, namely AR(1)-GJR-GARCH allows to test spillover effects and investigate how much conditional variance individual country $j$ has been explained respectively by Global Factor US (GF US), Regional Factor EU (RF EU), local factor (own market of country $j$ ) as well as the World Factor Oil Price (WF Oil).

The core empirical modeling and estimation framework in this paper is based on $\mathrm{Ng}$ (2000), Bekaert et al., (2005), and Christiansen (2004). More specifically, the four sources, namely pure local shocks of a country $j$, global US shocks, regional European

\footnotetext{
${ }^{4}$ Note: Weekly returns of indexes are calculated using following formula: $R_{t}=100 * \ln \left(\frac{P_{t}}{P_{t-1}}\right)$, where $P_{t}$ and $P_{t-1}$ respectively are logs of indexes at time $t$, and one period lag.
} 
shocks as well as shocks from oil price innovations are allowed for estimation of conditional volatility of country $j$ 's stock returns. The models and estimation framework follow $\mathrm{Ng}$ (2000) and Christiansen (2004) approaches mostly. In addition to that, my paper examines the mean and volatility spillover from oil shocks to country $j$ 's stock returns, too. Thus, on the four steps univariate autoregressive (AR)GJR-GARCH $(1,1)$ is applied. In order to get rid of serial correlation and to avoid ortogonalization, GJRGARCH model will evolve according to AR (1) process.

\section{Constant spillover models}

The spillover models are constructed in the following steps indicated below. The first step is to construct and estimate the bivariate model for Brent oil spot price including a constant and one period lagged return of oil price.

Step 1: World FactorOil Returns (WF Oil): The unconditional mean for oil returns in equation (1) changes according to the first order autoregressive (AR) process which allows us to avoid possible serial correlation. The unconditional variance evolves based on asymmetric GJR-GARCH $(1,1)$ which is specified equation (2):

$$
\begin{gathered}
R_{o i l, t}=\Phi_{0, o i l}+\Phi_{1, o i l} R_{o i l, t-1}+\epsilon_{o i l, t} \\
h_{o i l, t}=\omega_{o i l}+a_{1, o i l} \varepsilon_{o i l, t-1}^{2}+\beta_{o i l} h_{o i l, t-1}+\alpha_{2, o i l}^{*} \epsilon_{o i l, t-1}^{2} I_{o i l, t-1} \\
\epsilon_{o i l, t} \mid I_{t-1} \sim N\left(0, h_{t}\right),
\end{gathered}
$$

The terms $\Phi_{0, \text { oil }}$ and $\Phi_{1, \text { oil }}$ are parameter of estimates and $\epsilon_{\text {oil,t }}$ denote a real valued stochastic process or an idiosyncratic shock which is assumed normally, distributed with zero mean. The term $I_{t-1}$ is information set available through time t-1. Subsequently, the term $h_{\text {oil }, t}$ stands for conditional variance.

The model enables us to show how volatility behaves differently by having effects of good and bad news, where:

$$
\begin{aligned}
I_{\text {oil }, t-1}=1 \quad \text { if } \quad & \epsilon_{\text {oil }, t}<0, \\
& \omega_{\text {oil }}>0, \\
& a_{1, \text { oil }}, \beta_{\text {oil }}, a_{1, \text { oil }}+\frac{1}{2} \alpha_{2, \text { oil }}^{*} \geq 0 \text { and } \\
& a_{1, \text { oil }}+\beta_{\text {oil }}+\frac{1}{2} \alpha_{2, \text { oil }}^{*} \leq 1 .
\end{aligned}
$$

When $\alpha_{2}^{*}$ positive sign, then "bad" news seems to have a better effect than the "good" news. In other words, negative shocks have a more noticeable effect on volatility than positive shocks.

Step 2: Global Factor $U S$ (GF US): By following the same previous AR (1) specification and asymmetric GJR-GARCH model described in Step 1, the mean and conditional variance for the US stock returns can be through univariate model respectively, in equations (4) and (5);

$$
R_{U S, t}=\Phi_{0, U S}+\Phi_{1, U S} R_{U S, t-1}+\varphi_{U S} R_{o i l, t-1}+\vartheta_{U S} \epsilon_{o i l, t}+\epsilon_{U S, t}
$$




$$
\begin{gathered}
h_{U S, t}=\omega_{U S}+a_{1, U S} \epsilon_{U S, t-1}^{2}+\beta_{U S} h_{U S, t-1}+\alpha_{2, U S}^{*} \epsilon_{U S, t-1}^{2} I_{U S, t-1} \\
\epsilon_{U S, t} I_{t-1} \sim N\left(0, h_{t}\right),
\end{gathered}
$$

As in step one, the terms $\Phi_{0, U S}$ and $\Phi_{1, U S}$ are parameter of own US stock returns. Step two also includes effects from one period passed oil price returns, where estimated parameter is given by in $\varphi_{U S}$. additionally, and variables $\vartheta_{U S} \epsilon_{o i l, t}$ and $\epsilon_{U S, t}$ respectively, account for idiosyncratic oil shocks with estimated parameter and own US shocks.

Step 3: Regional Factor $E U(R F E U)$ : The univariate model for stock returns of sixteen European Monetary Union (EMU) countries stock market index can be expressed as follows:

$$
\begin{aligned}
& R_{E U, t}=\Phi_{0, E U}+\Phi_{1, E U} R_{E U, t-1}+\gamma_{U S} R_{U S, t-1}+\varphi_{E U,} R_{o i l, t-1}+\vartheta_{E U} \epsilon_{o i l, t}+\theta_{U S} \epsilon_{U S, t}+ \\
& \epsilon_{E U, t}
\end{aligned}
$$

The equation (7) indicates that European developed markets' stock returns correspondingly depend on its own one period lagged returns, one period past US returns, as well as one period lagged oil returns, where last two lagged returns claim mean spillovers for European advance stock markets. Eventually, the conditional variance equation for EU stock returns evolves according to $\operatorname{GJR}-\mathrm{GARCH}(1,1)$, where idiosyncratic EU shock $\epsilon_{E U, t}$ is normally distributed with zero mean;

$$
h_{E U, t}=\omega_{E U}+a_{1, E U} \varepsilon_{E U, t-1}^{2}+\beta_{E U} h_{E U, t-1}+\alpha_{2, E U}^{*} \epsilon_{E U, t-1}^{2} I_{E U, t-1}
$$

Eventually, idiosyncratic Oil price shocks and contemporary US residual $\epsilon_{U S, t}$ account for volatility spillovers for EU developed market.

Step 4: European Country j's stock returns: As the final step, the univariate return and volatility models are specified for each individual European stock returns. As previously, in order to avoid serial correlation, one period lagged return of each individual stock return is included and the conditional mean for a country $j$ is thus given as follows $(\mathrm{j}=1,2 \ldots 8)$;

$$
\begin{gathered}
R_{j, t}=c_{0, j}+c_{1, j} R_{j, t-1}+\gamma_{j} R_{U S, t-1}+\delta_{j} R_{E U, t-1}+\varphi_{j} R_{o i l, t-1}+ \\
+\theta_{j} \epsilon_{U S, t}+\psi_{j} \epsilon_{E U, t}+\vartheta_{j} \epsilon_{o i l, t}+\epsilon_{j, t}
\end{gathered}
$$

The first row (line) in equation (9) introduces the mean spillovers and parameter estimates $\gamma_{j}, \delta_{j}$ and $\varphi_{j}$ respectively to measure the significance the US, EU and Oil mean spillovers into each national stock market of European countries. The second raw (line) in equation (9), presents volatility spillovers from GF US, the RF EU and WF Oil and the following parameter estimates $\theta_{j}, \psi_{j}$ and $\vartheta_{j}$ empirically test the significance of volatility spillovers. The idiosyncratic shock, $\epsilon_{j, t}$ for country $j$ is also normally distributed and the conditional variance of the residual is specified below, where

$$
h_{j, t}=\omega_{j}+a_{1, j} \varepsilon_{j, t-1}^{2}+\beta_{j} h_{j, t-1}+\alpha_{2, j}^{*} \epsilon_{j, t-1}^{2} I_{j, t-1}
$$




\subsection{Volatility spillover effects: Variance ratios}

The unexpected returns can also be expressed by $\varepsilon_{t}$ as follows:

$$
\begin{gathered}
\varepsilon_{U S, t}=\epsilon_{U S, t}+\epsilon_{o i l, t} \\
\varepsilon_{E U, t}=\theta_{E U} \epsilon_{U S, t}+\vartheta_{E U} \epsilon_{o i l, t}+\epsilon_{E U, t} \\
\text { Country j's: } \varepsilon_{j, t}=\theta_{j} \epsilon_{U S, t}+\psi_{j} \epsilon_{E U, t} \epsilon_{, t}+\vartheta_{j} \epsilon_{o i l, t} \epsilon_{, t}+\epsilon_{E U, t}
\end{gathered}
$$

The terms $\epsilon_{U S, t}, \epsilon_{E U, t}$ and $\epsilon_{o i l, t}$ are assumed to be independent by construction. The last term in equation (13) accounts for remaining effects which are explained by innovations evolved in individual European stock markets. The conditional variance for unexpected returns can be calculated by taking variances of different terms in equation (13), and it is given below:

$$
\text { Country j's: } h_{j . t}=E\left(\epsilon_{U S, t} \mid \psi_{t-1}\right)=\theta_{j}^{2} h_{U S, t}+\psi_{j}^{2} h_{E U, t}+\vartheta_{j}^{2} h_{o i l, t}+\sigma_{j, t}^{2}
$$

The terms $h_{U S, t}, h_{o i l, t}$. and $h_{E U, t}$ respectively, denote squared US, EU and idiosyncratic oil market shocks. Consequently, the total variance for individual developing European Stock market consists of variances of Global Factor US (GF US), Regional Factor EU (RF EU), and idiosyncratic World Factor Oil price (WF Oil), as well as variance of its own returns.

urthermore, in order to measure the variances of the unexpected return of country $j$, estimated coefficients from unconditional models are utilized. By using equation (13), the variances can be ultimately computed and the expression for "variance ratios" is specified as follows:

$$
\begin{array}{r}
V R_{j, t}^{U S}=\frac{\theta_{j, t-1}^{2} \sigma_{U S, t}^{2}}{h_{j . t}} \\
V R_{j, t}^{E U}=\frac{\theta_{j, t-1}^{2} \sigma_{E U, t}^{2}}{h_{j . t}} \\
V R_{j, t}^{O I L}=\frac{\theta_{j, t-1}^{2} \sigma_{o i l, t}^{2}}{h_{j . t}} \\
V R_{j, t}^{O w n}=1-V R_{j, t}^{U S}-V R_{j, t}^{E U}-V R_{j, t}^{O I L}
\end{array}
$$

Equations (15), (16), and (17) quantify the variance ratios of various transmitted shocks in total conditional variances for a country $j$, and equation (18) simply denotes remaining variances which are explained by pure local factors.

\subsection{Asymmetric spillover tests on stock returns}

In order to examine how stock returns of eight (8) individual European countries react asymmetrically to changes in global and regional stock markets and oil markets, the equation (19) introduces asymmetric effects of investigated stock markets returns towards changes from GF US, RF EU and WF Oil effects, in terms of decrease and increase of stock returns and negative and positive effects of stock innovations on shocks. 


$$
\begin{gathered}
R_{j, t}=c_{0, j}+c_{1, j} R_{j, t-1}+\gamma_{0, j} R_{U S, t-1}^{-}+\gamma_{1, j} R_{U S, t-1}^{+}+\delta_{0, j} R_{E U, t-1}^{-}+\delta_{1, j} R_{E U, t-1}^{+}+ \\
\varphi_{1, j} R_{o i l, t-1}^{-}+\varphi_{1, j} R_{o i l, t-1}^{+}+\theta_{0, j} \epsilon_{U S, t}^{-}+\theta_{1, j} \epsilon_{U S, t}^{+}+\psi_{0, j} \epsilon_{E U, t}^{-}+\psi_{1, j} \epsilon_{E U, t}^{+}+\vartheta_{0, j} \epsilon_{o i l, t}^{-}+ \\
\vartheta_{1, j} \epsilon_{o i l, t}^{+}+\epsilon_{j, t}
\end{gathered}
$$

In equation (19), both lagged returns and shocks are allowed to have both negative and positive values. More specifically, the previously modeled mean spillovers are investigated by decomposing returns $R_{t-1}$ in two variables which respectively represents decrease $\left(R_{t-1}^{-}\right)$and increase $\left(R_{t-1}^{+}\right)$in returns of GF US, RF EU and WF Oil returns. In the same manner, volatility spillovers shocks can be distinguished as $\epsilon_{t}^{-}$and $\epsilon_{t}^{+}$which are a proxy for negative and positive shocks. Subsequently, each of the variables that accounts for asymmetric effects appeared in equation (19) is constructed as follows:

$$
\begin{gathered}
R_{t-1}^{-}=R_{t-1} \mathrm{If} R_{t-1}<0 \text { and zero }(0) \text { otherwise } \\
R_{t-1}^{+}=R_{t-1} \mathrm{If} R_{t-1}>0 \text { and zero }(0) \text { otherwise } \\
\epsilon_{t}^{-}=\epsilon_{t} \mathrm{If} \epsilon_{t}<0 \text { and zero }(0) \text { otherwise } \\
\epsilon_{t}^{+}=\epsilon_{t} \mathrm{If} \epsilon_{t}>0 \text { and zero }(0) \text { otherwise }
\end{gathered}
$$

\subsection{Instrumental variables in the spillover model}

In addition to unconditional spillover model the conditional spillover driven by instrumental economic variables introduced by $\mathrm{Ng}(2000)$ is also described by equations (20)-(23). The model includes parameters that relax the time varying constant spillover. As the degree of international relationships via trades change as well as the degree of regional integration evolves over time, it is apt to investigate how spillover weight parameters are captured by some local and regional instrumental variables. For that reason we allow the following model to account for the notion of conditionality mentioned above;

$$
\begin{aligned}
\gamma_{j, t-1} & =v^{i} X_{j, t-1}^{U S} \\
\theta_{j, t-1} & =w^{i} X_{j, t-1}^{U S} \\
\delta_{j, t-1} & =p^{i} X_{j, t-1}^{E U} \\
\psi_{j, t-1} & =q^{i} X_{j, t-1}^{E U}
\end{aligned}
$$

Where, $v^{\prime}$ and $w^{\prime}$ are $(3 \times 1)$ vectors of parameters, which quantify the impact of local information variables on the conditional spillover effects from global factor US, while $p^{\prime}$ and $q^{\prime}$ are also vector of parameters measuring spillover effects from regional European effect. The economic variables in $X_{i, t-1}^{U S}$ include currency of country $j$ 's constant exchange rate against US dollar, and total exports from and imports to US as a ratio of GDP of country $j$. Subsequently, the variables $X_{i, t-1}^{E U}$ include currency of a 13 
country $j$ 's constant change of exchange rate against EURO, and trade with sixteen European Monetary Union (EMU 16) countries as ratio of GDP of a country $j$. It should be mentioned that all the countries investigated in this paper are either non-Eurozone or EU members. Currency effects on volatility and correlation of stock markets have been widely studied. Shocks caused by exchange rate fluctuations can readily transmit to international financial markets. Moreover, economic integration is defined as the main motivation behind using the ratios of a trade country $j$ to US and EMU (16) to GDP $(\mathrm{Ng}, 2000)$.

\subsection{AR(1)-GJR-GARCH(1,1) - Dummy variable model}

The membership in European Union (EU) also led to development of stock exchange markets of the new member countries. In order to analyse the effect EU Enlargement on mean and volatility spillovers from regional European market, a dummy variable model is employed. The dummy variable is created such that, from September 8, 2000, to April 30, 2004, and from September 8, 2000, to December 31, 2006, the dummy 0, and from May 1, 2000, to March 30, 2012, and from January 8, 2000, to January 1, 2007, the dummy value 1 is applied respectively to account for the first and second wave of EU Accession of the aforementioned countries ${ }^{5}$. The unconditional AR(1)-GJR-GARCH $(1,1)$ Dummy variable model and variance quantifications are presented in the equations below:

$$
\begin{gathered}
R_{j, t}=c_{0, j}+c_{1, j} R_{j, t-1}+\gamma_{j} R_{U S, t-1}+\left(\delta_{0, j}+\delta_{1, j} D_{t-1}\right) R_{E U, t-1}+\varphi_{1, o i l} R_{o i l, t-1}+ \\
+\theta_{j} \epsilon_{U S, t}+\left(\psi_{0, j}+\psi_{1, j} D_{t-1}\right) \epsilon_{E U, t}+\vartheta_{j} \epsilon_{o i l, t}+\epsilon_{j, t} \\
V R_{j, t}^{E U, d u m}=\frac{\left(\psi_{0, j}+\psi_{1, j} D_{t-1}\right)^{2} \sigma_{e u, t}^{2}}{h_{j, t}} \\
V R_{j, t}^{O W n}=1-V R_{j, t}^{U S}-V R_{j, t}^{E U, d u m}-V R_{j, t}^{O I L}
\end{gathered}
$$

Thus, the AR(1)-GJR-GARCH (1,1) dummy model specified in equation (24) and relevant variance ratios will aim to examine the possible effect (decrease or increase) in constant spillover parameters.

\section{Empirical results}

\subsection{Constant spillover model}

The empirical findings for the mean and return volatility spillovers shown in Table 2 indicate that the first-order autocorrelation parameters of individual countries are significant for Poland and the Ukraine only. As previously specified in equation (9), the spillover effects into national stock returns are transmitted by one period lagged returns and market shocks from the US and EU stock markets, as well as oil market.

\footnotetext{
${ }^{5}$ Czech Republic, Hungary, Poland, Baltic States, Slovakia, and Slovenia joined to EU in the first wave of EU enlargement in 2004. The second wave defines the membership of Romania and Bulgaria in 2007.
} 
Table 2: The constant spillover model estimation results for an individual country j's stock returns over the entire sample period (September 2000 - March 2012)

\begin{tabular}{|c|c|c|c|c|c|c|c|c|}
\hline & Croatia & Czech $^{6}$ & Hungary & Poland & Romania & Russia & Turkey & Ukraine \\
\hline \multirow[t]{3}{*}{$c_{0}$} & $0.288 \#$ & $0.336 *$ & $0.282 \#$ & $0.207^{\wedge}$ & $0.359 \#$ & $0.349 \#$ & 0.215 & 0.236 \\
\hline & $(0.014)$ & $(0.001)$ & (0.039) & $(0.081)$ & $(0.018)$ & $(0.020)$ & $(0.250)$ & $(0.267)$ \\
\hline & [0.116] & [0.107] & [0.137] & [0.119] & {$[0.152]$} & {$[0.150]$} & [0.187] & [0.021] \\
\hline \multirow[t]{3}{*}{$c_{1}$} & 0.058 & -0.070 & -0.062 & $-0.100 \#$ & -0.025 & -0.074 & -0.081 & $0.105 \#$ \\
\hline & $(0.207)$ & $(0.098)$ & $(0.148)$ & $(0.020)$ & $(0.551)$ & $(0.061)$ & $(0.104)$ & $(0.032)$ \\
\hline & [0.046] & [0.042] & [0.043] & [0.043] & [0.044] & {$[0.040]$} & {$[0.050]$} & [0.049] \\
\hline \multirow[t]{3}{*}{$\delta$} & $0.134^{\wedge}$ & -0.031 & 0.116 & -0.031 & $0.196 \#$ & -0.004 & 0.103 & 0.464 \\
\hline & $(0.056)$ & $(0.658)$ & $(0.141)$ & $(0.698)$ & $(0.044)$ & $(0.958)$ & $(0.386)$ & $(0.056)$ \\
\hline & {$[0.071]$} & {$[0.070]$} & {$[0.080]$} & {$[0.080]$} & {$[0.092]$} & {$[0.083]$} & [0.119] & {$[0.078]$} \\
\hline \multirow[t]{3}{*}{$\gamma$} & -0.035 & $-0.166 \#$ & 0.807 & $-0.236 *$ & -0.121 & 0.066 & -0.002 & $-0.274 \#$ \\
\hline & $(0.603)$ & $(0.015)$ & $(0.067)$ & $(0.100)$ & $(0.234)$ & $(0.528)$ & $(0.187)$ & $(0.023)$ \\
\hline & {$[0.068]$} & [0.068] & [0.079] & {$[0.083]$} & [0.101] & {$[0.105]$} & {$[0.135]$} & [0.121] \\
\hline \multirow[t]{3}{*}{$\varphi$} & 0.024 & $-0.054 \#$ & 0.047 & $0.072 *$ & $0.077 \#$ & $0.180^{*}$ & 0.049 & $-0.096 *$ \\
\hline & $(0.289)$ & $(0.020)$ & $(0.102)$ & $(0.009)$ & $(0.015)$ & $(0.005)$ & $(0.320)$ & $(0.007)$ \\
\hline & {$[0.023]$} & [0.023] & [0.028] & {$[0.028]$} & [0.032] & [0.039] & {$[0.050]$} & [0.036] \\
\hline \multirow[t]{3}{*}{$\psi$} & $0.760^{*}$ & $1.092 *$ & $1.239 *$ & $1.203^{*}$ & $0.923^{*}$ & $0.701^{*}$ & $1.009^{*}$ & $0.301 *$ \\
\hline & $(0.000)$ & $(0.000)$ & $(0.000)$ & $(0.000)$ & $(0.000)$ & $(0.000)$ & $(0.000)$ & $(0.000)$ \\
\hline & {$[0.066]$} & {$[0.056]$} & [0.068] & {$[0.071]$} & {$[0.076]$} & {$[0.092]$} & {$[0.120]$} & [0.078] \\
\hline \multirow[t]{3}{*}{$\theta$} & $0.431 *$ & $0.780 *$ & $0.866^{*}$ & $0.979 *$ & $0.605^{*}$ & $0.782 *$ & $1.046^{*}$ & $0.280 *$ \\
\hline & $(0.000)$ & $(0.000)$ & $(0.000)$ & $(0.000)$ & $(0.000)$ & $(0.000)$ & $(0.000)$ & $(0.000)$ \\
\hline & {$[0.045]$} & {$[0.035]$} & [0.039] & {$[0.041]$} & {$[0.058]$} & {$[0.051]$} & {$[0.088]$} & [0.063] \\
\hline \multirow[t]{3}{*}{$\vartheta$} & $0.138 *$ & $0.179 *$ & $0.202 *$ & $0.231 *$ & $0.227 *$ & $0.364 *$ & $0.212 *$ & 0.069 \\
\hline & $(0.000)$ & $(0.000)$ & $(0.000)$ & $(0.000)$ & $(0.000)$ & $(0.000)$ & $(0.000)$ & $(0.175)$ \\
\hline & {$[0.025]$} & [0.023] & [0.031] & {$[0.027]$} & [0.049] & {$[0.037]$} & {$[0.050]$} & [0.051] \\
\hline \multirow[t]{3}{*}{$\omega$} & 1.687 & 0.379 & 2.589 & $0.341 \#$ & $0.389^{\wedge}$ & 0.499 & $0.189 \#$ & 0.947 \\
\hline & $(0.000)$ & $(0.005)$ & $(0.001)$ & $(0.039)$ & $(0.052)$ & $(0.006)$ & $(0.050)$ & $(0.002)$ \\
\hline & [0.466] & [0.133] & {$[0.080]$} & {$[0.165]$} & {$[0.021]$} & [0.182] & {$[0.096]$} & [0.303] \\
\hline \multirow[t]{3}{*}{$\alpha$} & $0.158 *$ & $0.125^{*}$ & 0.063 & $0.115^{*}$ & $0.104 *$ & $0.122 *$ & $0.029 \#$ & $0.236^{*}$ \\
\hline & $(0.002)$ & $(0.000)$ & $(0.215)$ & $(0.003)$ & $(0.000)$ & $(0.002)$ & $(0.038)$ & $(0.000)$ \\
\hline & [0.052] & [0.037] & {$[0.051]$} & [0.039] & [0.031] & {$[0.040]$} & {$[0.014]$} & [0.039] \\
\hline \multirow[t]{3}{*}{$\alpha^{*}$} & 0.108 & -0.027 & $0.161 \#$ & -0.005 & -0.020 & 0.001 & $0.058^{*}$ & 0.06 \\
\hline & $(0.130)$ & $(0.468)$ & $(0.025)$ & $(0.893)$ & $(0.454)$ & $(0.998)$ & $(0.001)$ & $(0.287)$ \\
\hline & {$[0.071]$} & [0.038] & {$[0.071]$} & {$[0.041]$} & [0.027] & {$[0.037]$} & {$[0.018]$} & [0.061] \\
\hline \multirow[t]{3}{*}{$\beta$} & $0.606^{*}$ & $0.836^{*}$ & $0.619^{*}$ & $0.853^{*}$ & $0.884^{*}$ & $0.849^{*}$ & $0.936^{*}$ & $0.767 *$ \\
\hline & $(0.000)$ & $(0.000)$ & $(0.000)$ & $(0.000)$ & $(0.000)$ & $(0.000)$ & $(0.000)$ & $(0.000)$ \\
\hline & {$[0.072]$} & [0.039] & [0.098] & {$[0.036]$} & {$[0.028]$} & {$[0.027]$} & {$[0.007]$} & [0.017] \\
\hline
\end{tabular}

Note: $P$ values and std.errors are in the parentheses and brackets, whilst $*$, \#, and $\wedge$ represent significance level at 1\%, 5\% and $10 \%$, respectively

\footnotetext{
${ }^{6}$ The Czech Republic appears in Tables abbreviated as Czech only.
} 
According to the scale and p-values of the parameter estimated, and the strong evidences of volatility spillovers from the US and EU stock markets, as well as oil market, are found to be highly significant for all national stock markets (p-value of 0.000) The parametric Wald tests of no volatility spillovers on stock returns are also rejected (Table 3). The null hypotheses of joined Wald tests employed for the purpose of estimation is given below;

$$
\begin{gathered}
\mathrm{H}_{0}^{1}: \varphi_{j}=\vartheta_{j}=0: \text { No Oil prices spillover effects on stock returns } \\
\mathrm{H}_{0}^{2}: \gamma_{j}=\theta_{j}=0: \text { No Global US spillover effects on stock returns } \\
\mathrm{H}_{0}^{3}: \delta_{j}=\psi_{j}=0: \text { No Regional EU spillover effects on stock returns } \\
\mathrm{H}_{0}^{4}: \varphi_{j}=\delta_{j}=\gamma_{j}=0: \text { No mean spillover effects on stock returns } \\
\mathrm{H}_{0}^{5}: \vartheta_{j}=\theta_{j}=\psi_{j}=0: \text { No volatility spillover effects on stock returns }
\end{gathered}
$$

Table 3: Wald tests for constant spillover model for entire sample period ${ }^{7}$ from September 2000 - March 2012)

\begin{tabular}{cccccc}
\hline & Wald $_{1}$ & Wald $_{2}$ & Wald $_{3}$ & Wald $_{4}$ & Wald $_{2}$ \\
\hline CRO & $14.797^{*}$ & $46.178^{*}$ & $67.533^{*}$ & $2.201^{\wedge}$ & $96.515^{*}$ \\
& $(0.001)$ & $(0.000)$ & $(0.00)^{*}$ & $(0.086)$ & $(0.000)$ \\
CZE & $31.864^{*}$ & $244.226^{*}$ & $194.387^{*}$ & $5.164^{*}$ & $302.17^{*}$ \\
& $(0.000)$ & $(0.000)$ & $(0.000)$ & $(0.002)$ & $(0.000)$ \\
HUN & $20.727^{*}$ & $242.231^{*}$ & $168.936^{*}$ & 4.199 & $466.16^{*}$ \\
& $(0.000)$ & $(0.000)$ & $(0.000)$ & $(0.056)$ & $(0.000)$ \\
POL & $39.776^{*}$ & $319.601^{*}$ & $143.008^{*}$ & $7.549^{*}$ & $418.02^{*}$ \\
& $(0.001)$ & $(0.000)$ & $(0.000)$ & $(0.001)$ & $(0.000)$ \\
ROM & $25.480^{*}$ & $56.351^{*}$ & $79.565^{*}$ & $4.217^{*}$ & $133.75^{*}$ \\
& $(0.000)$ & $(0.000)$ & $(0.000)$ & $(0.006)$ & $(0.000)$ \\
RUS & $52.362^{*}$ & $119.239^{*}$ & $28.973^{*}$ & $2.847 \#$ & $142.51^{*}$ \\
& $(0.000)$ & $(0.000)$ & $(0.000)$ & $(0.037)$ & $(0.000)$ \\
TUR & $9.4069^{*}$ & $69.932^{*}$ & $35.113^{*}$ & 1.163 & $75.585^{*}$ \\
& $(0.002)$ & $(0.000)$ & $(0.000)$ & $(0.322)$ & $(0.000)$ \\
\multirow{2}{*}{ UKR } & $4.9343^{*}$ & $14.665^{*}$ & $21.380^{*}$ & $17.796^{*}$ & $16.151^{*}$ \\
& $(0.008)$ & $(0.000)$ & $(0.000)$ & $(0.000)$ & $(0.000)$ \\
\hline
\end{tabular}

Note: $P$ values and std. errors are in the parentheses and brackets, whilst $*$, \#, and ${ }^{\wedge}$ represent significance level at 1\%, 5\% and $10 \%$, respectively.

The presence of significant mean spillovers from the US stock markets is found with negative coefficients for Poland, Czech Republic and the Ukraine. The weak mean spillover effect from regional EU market is statistically significant for Romania. Thus, results show some mean spillover effects from global US, however, the mean spillovers from regional market can be considered negligible. According to coefficient estimates

\footnotetext{
${ }^{7}$ Wald $_{1}$, Wald $_{2}$, Wald $_{3}$, Wald $_{4}$ and Wald 5 tests are $\chi 2(2)$ distributed under the aforementioned null hypothesis.
} 
summarized in Table 2, the mean spillover from oil returns significantly influences stock returns of the Czech Republic, Poland, Romania and Russia, and the Wald tests are rejected, accordingly. Judged by the scale of the coefficient, the lagged oil return is found to be highly positive and significant for Russia $\left(\varphi_{o i l}, 0.180\right)$. This finding can be interpreted by the fact that Russia is the only oil exporting country amongst the eight European countries investigated. In other words, oil returns seem to highly and positively drive Russian stock returns. The volatility spillover effects driven by oil shocks area appeared to be strongly significant and associated with positive parameter signs for all countries, except for the Ukraine. GJR-GARCH $(1,1)$ model also captures asymmetric effects for stock returns ${ }^{8}$. The presence of asymmetric effects is found to be significant only for stock returns of Hungary and Turkey (Table 2). In other words, some evidences of leverage effect (Ding et. al., 1993), implying that negative shocks (bad news) tend to influence stock returns more than positive shocks (good news) are reported only in the cases of Hungary and Turkey.

The effects of volatility spillovers for a country $j$ are evaluated according to variance ratios namely, VR-US from global factor, VR-EU from regional factor, VR-OIL from world factor and local VR-OWN are quantified and reported in Table 4. The variance ratios assess the proportions of unexpected returns in total conditional variance. The US volatility spillovers are found to be the most dominating factor for conditional variance of unexpected returns for all investigated countries except for Croatia and Romania. More specifically, on average $9.4 \%-26.7 \%$ of volatility spillovers are contributed by US market shocks.

Table 4: Summary statistics for variance ratios for the entire period (from Sep 2000-Mar2012)

\begin{tabular}{cccccccccc}
\hline & & CRO & CZE & HUN & POL & ROM & RUS & TUR & UKR \\
\hline VR EU & M & 22.713 & 26.716 & 24.583 & 16.851 & 20.055 & 10.866 & 13.855 & 6.367 \\
& SD & 0.260 & 0.276 & 0.261 & 0.198 & 0.225 & 0.160 & 0.199 & 0.008 \\
VR US & M & 16.187 & 26.798 & 25.028 & 24.837 & 18.707 & 21.726 & 24.791 & 9.492 \\
& SD & 0.206 & 0.260 & 7.077 & 0.258 & 0.211 & 0.244 & 0.276 & 0.180 \\
VR OIL & M & 8.219 & 7.802 & 0.070 & 20.386 & 9.576 & 16.932 & 6.042 & 3.132 \\
& SD & 0.145 & 0.311 & 0.115 & 0.219 & 0.146 & 0.210 & 0.107 & 0.078 \\
VR OWN & M & 52.880 & 38.681 & 43.331 & 37.923 & 51.656 & 50.474 & 55.310 & 81.008 \\
& SD & 0.345 & 0.311 & 0.322 & 0.292 & 0.325 & 0.334 & 0.242 & 0.277 \\
\hline
\end{tabular}

Note: $M$ for mean and SD for standard deviation.

In contrast, the EU market shocks account on average for $6.3 \%-25.7 \%$ of volatility spillovers, which is relatively less than global US volatility spillovers. The result aids to answer the second research question that the US stock returns, thereby the US S\&P 500 index has most magnitude effect on national stock markets of European national markets. Judged by oil volatility spillover coefficients, the highest oil volatility

\footnotetext{
8 Symmetrical AR(-1) GARCH $(1,1)$ model is also estimated and reported in Table 1 in Appendix. Judged by the signs and scale of significant coefficients, it should be noted that symmetrical and asymmetrical models present almost similar results for all eight individual stock markets.
} 
spillovers effects are found in the case of Russia (VR OIL=16.9\%). Finally, purely local shocks are more pronounced compared to external shocks, and on average for CEE countries, means of local shocks are relatively small compared to other European countries. The interpretation of this is more likely due to the fact that CEE countries are most integrated into the regional, and are considered to be the most highly emerged stock markets amongst other examined countries

Additionally, I also empirically tested the purely regional EU and global US mean and spillover effects by excluding the oil price effects ${ }^{9}$, and eventually, quantitative evaluations the variance ratios are computed and reported in Table 5.

Table 5: Summary statistics (Mean and std. dev.) for Variance ratios while excluding Oil effect over entire period (from September 2000-March 2012)

\begin{tabular}{cccccccccc}
\hline & & CRO & CZE & HUN & POL & ROM & RUS & TUR & UKR \\
\hline \multirow{2}{*}{ VR EU } & Mean (\%) & 25.569 & 30.259 & 27.312 & 24.342 & 21.681 & 16.543 & 16.557 & 8.139 \\
& Std. dev & 0.281 & 0.299 & 0.279 & 0.257 & 0.256 & 0.221 & 0.227 & 0.158 \\
\multirow{2}{*}{ VR US } & Mean (\%) & 18.624 & 29.593 & 27.145 & 31.348 & 19.894 & 26.212 & 30.730 & 10.936 \\
& Std. dev & 0.233 & 0.283 & 0.200 & 0.300 & 0.239 & 0.281 & 0.299 & 0.207 \\
\multirow{2}{*}{ VR OWN } & Mean (\%) & 55.805 & 40.146 & 45.542 & 44.276 & 58.423 & 57.243 & 56.578 & 80.923 \\
& Std. dev & 0.341 & 0.324 & 0.331 & 0.329 & 0.333 & 0.331 & 0.344 & 0.276 \\
\hline
\end{tabular}

The assessment by excluding oil effect also confirms the dominating role of US volatility spillovers over those from EU spillover effects. In other words, the unexpected returns of shocks on investigated European stock markets are mostly driven by global US volatility effects and local shocks.

\subsection{Sensitivity analysis}

In the previous section I have shown that the mean spillover effects from regional EU stock market are statistically insignificant. This can be interpreted by the existence of high correlation $(0.828)$ between the US and EU stock market. Taking into account the reason of such a high correlation, the so called sensitivity analysis is implemented. The analysis is mainly based onomitting the U.S one period lagged return in estimation framework by applying redundant variable test. Table 6 reports the results. The findings indicate that with exclusion of US one period lagged return, the mean spillover effects from regional market becomes significant for Croatia, Czech Republic, Hungary, Poland, and the Ukraine. None of the changes are reported for oil mean spillover effects. Thus, the sensitivity analysis throughout redundant variable tests draws attention to several brief conclusion that by omitting the US one lagged return yield the EU mean spillover effects to have strong evidences towards stock returns of individual European emerging and developing economies.

\footnotetext{
${ }^{9}$ The empirical results and Wald tests are reported in Table 2 and 3 Appendix.
} 
Table 6: Estimated results by Exclusion US effect (2000-2012)

\begin{tabular}{ccc}
\hline & $\delta$ & $\varphi$ \\
\hline Croatia & $0.108 \#$ & 0.025 \\
& $(0.018)$ & $(0.274)$ \\
Czech & {$[0.045]$} & {$[0.023]$} \\
& $0.097 \#$ & $0.044^{\wedge}$ \\
& $(0.032)$ & $(0.054)$ \\
Hungary & {$[0.023$} & {$[0.055]$} \\
& $0.176^{*}$ & 0.045 \\
& $(0.002)$ & $(0.110)$ \\
Poland & {$[0.058]$} & {$[0.028]$} \\
& $0.144^{*}$ & $0.064 \#$ \\
Romania & $(0.003)$ & $(0.019)$ \\
& {$[0.049]$} & {$[0.027]$} \\
& $0.108^{\wedge}$ & $0.080 \#$ \\
Russia & $(0.053)$ & $(0.011)$ \\
& {$[0.058]$} & {$[0.031]$} \\
& 0.040 & $0.106^{*}$ \\
Turkey & $(0.391)$ & $(0.006)$ \\
& {$[0.047]$} & {$[0.039]$} \\
Ukraine & 0.101 & 0.050 \\
& $(0.185)$ & $(0.310)$
\end{tabular}

significance level at $1 \%, 5 \%$ and $10 \%$, respectively.

Judging by obtained signs and scales of coefficients in the Table 6 , for some countries, the strong indication of EU mean spillovers using redundant variable test seems to be interpreted by previous high correlation $(0.828)$ between the US and EU stock returns. It is worth to note that high correlation between two explanatory variables, namely the US and EU lagged returns, possibly introduce Multicollinearity problem which cannot be ignored (Brook, 2008).

\subsection{Asymmetric spillover effects on stock returns}

Although the asymmetric term is associated in primary spillover models and is found to be significant for some countries (Hungary and Turkey), the approach mentioned above sheds more light on exploring the response of stock returns separately towards negative and positive market shocks and upturns and downturns in lagged returns transmitted to global (GF US), regional (RF EU), and world factors (WF Oil). Since the mean specifications for global and regional factors are negligible, the asymmetric effects from all transmitted market shocks and only from one lagged oil price returns are reported and analyzed. The Table7 summarized the estimation results for asymmetric tests on national stock returns. Except for Croatia, all other stock markets respond 
asymmetrically to upturns and downturns in oil price, where the estimated coefficient of $R_{\text {oil }, t-1}^{+}$and $\varphi_{1}$ is highly significant ${ }^{10}$.

$$
\begin{aligned}
& R_{j, t}=c_{0, j}+c_{1, j} R_{j, t-1}+\gamma_{0, j} R_{U S, t-1}^{-}+\gamma_{1, j} R_{U S, t-1}^{+}+\delta_{0, j} R_{E U, t-1}^{-}+\delta_{1, j} R_{E U, t-1}^{+}+ \\
& \varphi_{1, j} R_{o i l, t-1}^{-}+\varphi_{1, j} R_{o i l, t-1}^{+}+\theta_{0, j} \epsilon_{U S, t}^{-}+\theta_{1, j} \epsilon_{U S, t}^{+}+\psi_{0, j} \epsilon_{E U, t}^{-}+\psi_{1, j} \epsilon_{E U, t}^{+}+\vartheta_{0, j} \epsilon_{o i l, t}^{-}+ \\
& \vartheta_{1, j} \epsilon_{o i l, t}^{+}+\epsilon_{j, t}
\end{aligned}
$$

\begin{tabular}{|c|c|c|c|c|c|c|c|c|}
\hline & Croatia & Czech & Hungary & Poland & Romania & Russia & Turkey & Ukraine \\
\hline \multirow[t]{3}{*}{$\varphi_{0}$} & 0.009 & $-0.054 \#$ & 0.047 & $0.072 *$ & $0.077 \#$ & $0.110^{*}$ & 0.049 & -0.096 \\
\hline & $(0.833)$ & $(0.020)$ & $(0.102)$ & $(0.009)$ & $(0.015)$ & $(0.005)$ & $(0.320)$ & $(0.007)$ \\
\hline & {$[0.045]$} & {$[0.046]$} & [0.052] & {$[0.050]$} & {$[0.058]$} & {$[0.067]$} & {$[0.082]$} & {$[0.078]$} \\
\hline \multirow[t]{3}{*}{$\varphi_{1}$} & 0.030 & $1.092 *$ & $1.239^{*}$ & $1.203^{*}$ & $0.923^{*}$ & $0.701 *$ & $1.009^{*}$ & $0.301^{*}$ \\
\hline & $(0.528)$ & $(0.000)$ & $(0.000)$ & $(0.000)$ & $(0.000)$ & $(0.000)$ & $(0.000)$ & $(0.000)$ \\
\hline & [0.030] & [0.047] & [0.067] & [0.060] & {$[0.065]$} & [0.068] & [0.100] & [0.080] \\
\hline \multirow[t]{3}{*}{$\psi_{0}$} & $0.872 *$ & $0.780^{*}$ & $0.866^{*}$ & $0.979 *$ & $0.605^{*}$ & $0.782 *$ & $1.046^{*}$ & $0.280^{*}$ \\
\hline & $(0.000)$ & (0.000) & $(0.000)$ & $(0.000)$ & $(0.000)$ & $(0.000)$ & $(0.000)$ & $(0.000)$ \\
\hline & [0.132] & [0.089] & [0.108] & [0.115] & {$[0.126]$} & {$[0.165]$} & [0.214] & [0.137] \\
\hline \multirow[t]{3}{*}{$\psi_{1}$} & $0.636^{*}$ & $0.179 *$ & $0.202 *$ & $0.231 *$ & $0.227 *$ & $0.364 *$ & $0.212 *$ & 0.069 \\
\hline & $(0.000)$ & (0.000) & $(0.000)$ & $(0.000)$ & $(0.000)$ & $(0.000)$ & $(0.000)$ & $(0.175)$ \\
\hline & [0.133] & [0.122] & [0.142] & [0.139] & [0.180] & [0.210] & [0.224] & [0.215] \\
\hline \multirow[t]{3}{*}{$\theta_{0}$} & $0.554 *$ & $0.379^{*}$ & $2.589^{*}$ & $0.341 \#$ & $0.389^{\wedge}$ & $0.499 *$ & $0.189 \#$ & $0.947 *$ \\
\hline & $(0.000)$ & $(0.005)$ & $(0.001)$ & $(0.039)$ & $(0.052)$ & $(0.006)$ & $(0.050)$ & $(0.002)$ \\
\hline & [0.072] & {$[0.056]$} & [0.061] & [0.066] & [0.100] & [0.090] & {$[0.156]$} & [0.113] \\
\hline \multirow{3}{*}{$\theta_{1}$} & $0.248^{*}$ & $0.125^{*}$ & 0.063 & $0.115^{*}$ & $0.104 *$ & $0.122 *$ & $0.029 \#$ & $0.236^{*}$ \\
\hline & $(0.008)$ & $(0.000)$ & $(0.215)$ & $(0.003)$ & $(0.000)$ & $(0.002)$ & $(0.038)$ & $(0.000)$ \\
\hline & [0.093] & [0.081] & [0.094] & [0.091] & [0.141] & [0.123] & [0.171] & [0.157] \\
\hline \multirow[t]{3}{*}{$\vartheta_{0}$} & 0.086 & -0.027 & $0.161 \#$ & -0.005 & -0.020 & 0.001 & $0.058^{*}$ & 0.067 \\
\hline & $(0.087)$ & $(0.468)$ & $(0.025)$ & $(0.893)$ & $(0.454)$ & $(0.998)$ & $(0.001)$ & $(0.287)$ \\
\hline & {$[0.057]$} & [0.042] & [0.057] & {$[0.050]$} & [0.072] & {$[0.067]$} & [0.096] & {$[0.086]$} \\
\hline \multirow[t]{3}{*}{$\vartheta_{1}$} & $0.181^{*}$ & $0.836^{*}$ & $0.619^{*}$ & $0.853^{*}$ & $0.887^{*}$ & $0.849 *$ & $0.936^{*}$ & $0.767^{*}$ \\
\hline & $(0.002)$ & $(0.000)$ & $(0.000) \quad(0.000)$ & $(0.000)$ & )$(0.000)$ & $(0.000)$ & $(0.000)$ & \\
\hline & [0.048] & [0.061] & {$[0.060]$} & {$[0.056]$} & {$[0.064]$} & {$[0.087]$} & [0.104] & [0.096] \\
\hline
\end{tabular}

Table 7: Estimated coefficients for the asymmetric spillover model, Sep 2000 Mar 2012

Note: $P$ values and std. errors are in the parentheses and brackets, whilst $*, \#$, and ${ }^{\wedge}$ represent significance level at 1\%, 5\% and 10\%, respectively.

The coefficients of $\mathrm{R}_{\mathrm{oil}, \mathrm{t}-1}^{-}$and $\varphi_{0}$ are found to be significant for the Czech Republic, Poland, Romania and Russia. In other words, it seems that the increase in oil returns has a greater effect rather than the decrease, and the magnitude of increase is greater for countries such as Poland, Czech Republic and Russia. The Wald test $\left(\mathrm{H}_{0}^{5}: \varphi_{0}=\varphi_{1}\right)$ of no oil shocks, however, is rejected for Romania and the Ukraine only. The results in Table 7 also indicate that stock markets of all the European emerging and developing countries except for Croatia respond asymmetrically to oil shocks. In spite of that, Romania, Russia and the Ukraine seem to respond significantly only to positive shocks, however, the stock returns of the Czech Republic, Hungary, Poland, and Turkey significantly depend on decrease and increase oil commodity oil price. The evidence is

${ }^{10}$ Note: the constant one period own lagged of individual countries are not reported in estimation results. 
that stock returns of individual countries tend to asymmetrically react to oil price shocks.

Furthermore, some indication of asymmetric existences towards global US and regional EU market shocks is recorded, too. Strong evidences of asymmetric response for US and EU contemporary residuals specified with negative $\left(\epsilon_{U S, t}^{-}\right.$and $\left.\epsilon_{E U, t}^{-}\right)$and positive $\left(\epsilon_{U S, t}^{+}\right.$and $\left.\epsilon_{E U, t}^{+}\right)$shocks are obtained. Based on the significant coefficient values, the negative shocks in both US and EU markets have more effects than positive shocks, implying that investors tend to react sharply to the negative shocks rather than the positive ones.

Despite the fact that regression coefficients appeared strongly for contemporary residuals from oil market as well as the US and EU stock markets, the joined Wald tests are not rejected in most of the cases. More specifically, in the case of regional EU shocks, the joined Wald tests of no asymmetric responses to EU shocks are rejected only for Hungary, Poland, and Russia at 5\% significance level. Not surprisingly, asymmetric responses towards negative shocks are more substantial thanks to positive shocks caused by regional EU residuals in the cases of Hungary, Poland, and Russia. In addition, Russia is the only market to respond significantly to oil price shocks, yet at $10 \%$ significance level. Moreover, the asymmetric shocks from US market are reported to be jointly significant only in the cases of Croatia and Romania. Taking into account the empirical findings fromWald test results, some evidences of asymmetric effects can be concluded (Table 4 in Appendix). However, the stock returns of the European emerging and developing markets do not react asymmetrically to either contemporary residuals or returns in most of the cases.

\subsection{Conditional spillover model results}

In order to evaluate performance of spillover intensities caused by global and regional stock market, conditional spillover modelspecified by equations (20)-(23) are relevantly explored for eight individual European countries. For investigation of behavior of EU and US spillovers, instrumental variables such as exchange rates and total trade/GDP are applied.

The results shown in Table 8 indicate that total trade to GDP ratio with positive coefficient (0.973) is the only significant variable explaining the EU conditional spillover effects for Croatia. Similar arbitrary empirical results are obtained for the Czech Republic and Romania. More specifically, in the case of the Czech Republic, US conditional mean spillovers and EU volatility spillovers are significantly driven by exchange rate changes, with coefficients of -0.630 and 1.122 .

On the other hand, for Romania, the US conditional mean spillover effect is explained by total trade/GDP ratio with corresponding positive coefficient of 0.159 . Moreover, both US conditional mean and volatility spillovers are not found to be strong in the case of Hungary and Poland. The exchange rate change is also a strong proxy in explaining the behavior of EU conditional volatility transmissions for Poland, while the total trade/GDP is a strong proxy in the case of Hungary. For both Hungary and Poland, 
conditional mean spillovers from regional markets are reported to be significantly introduced by two macroeconomic instrumental variables. Still more interesting is the case of Russia, both EU conditional mean and volatility spillovers are not found to be driven by constructed instruments. However, the estimated instruments for explaining the parameters of US conditional mean and volatility spillover effects are found to be highly significant and positive. There is strong empirical evidence that US conditional spillover intensities can be explained by exchange rate fluctuations of USD and ruble, as well as by the total trade between US and Russia. When it comes to findings for Turkey, only exchange rate changes, namely LIRA/USD and LIRA/EURO can significantly impact the US and EU conditional spillover parameters.

Table 8: Estimated coefficients for the conditional spillover model, from Sep 2000 to Mar 2012

\begin{tabular}{|c|c|c|c|c|c|c|c|c|c|}
\hline & & $\mathrm{CRO}$ & $\mathrm{CZE}$ & HUN & POL & ROM & RUS & TUR & UKR \\
\hline \multicolumn{10}{|c|}{ US conditional Mean spillover } \\
\hline \multirow[t]{3}{*}{ Constant } & $v_{0}$ & 2.555 & -1.668 & 5.520 & 1.140 & 4.446 & -4.982 & 0.835 & $-6.972^{\wedge}$ \\
\hline & & $(0.352)$ & $(0.724)$ & $(0.196)$ & $(0.819)$ & $(0.156)$ & $(0.140)$ & $(0.750)$ & $(0.077)$ \\
\hline & & {$[2.748]$} & {$[4.731]$} & {$[4.271]$} & [1.140] & [3.136] & {$[3.376]$} & [2.627] & {$[3.957]$} \\
\hline \multirow{3}{*}{$\begin{array}{c}\text { Exchange rate } \\
\text { changes }\end{array}$} & $v_{I}$ & -0.774 & $-0.630 \#$ & -0.497 & -0.097 & 1.199 & $2.916^{*}$ & $1.782 *$ & $1.683 \#$ \\
\hline & & $(0.108)$ & $(0.036)$ & $(0.324)$ & $(0.872)$ & $(0.080)$ & $(0.004)$ & $(0.000)$ & $(0.023)$ \\
\hline & & {$[0.482]$} & {$[0.300]$} & [0.504] & [0.608] & {$[0.687]$} & {$[1.005]$} & [0.363] & {$[0.742]$} \\
\hline \multirow[t]{3}{*}{ Trade to GDP ratio } & $v_{2}$ & 0.084 & 0.353 & 0.241 & 0.071 & $0.159 \#$ & $0.450 *$ & 0.119 & -0.340 \\
\hline & & $(0.728)$ & $(0.405)$ & $(0.483)$ & $(0.772)$ & $(0.044)$ & $(0.003)$ & $(0.635)$ & $(0.136)$ \\
\hline & & {$[0.244]$} & {$[0.424]$} & [0.344] & {$[0.460]$} & [0.298] & {$[0.123]$} & [0.252] & {$[0.228]$} \\
\hline \multicolumn{10}{|c|}{ EU conditional Mean spillover } \\
\hline \multirow[t]{3}{*}{ Constant } & $p_{0}$ & -0.061 & 4.037 & -33.459 & 3.606 & 0.039 & 1.847 & 0.305 & -3.212 \\
\hline & & $(0.962)$ & $(0.648)$ & $(0.019)$ & $(0.523)$ & $(0.993)$ & $(0.794)$ & $(0.936)$ & $(0.452)$ \\
\hline & & [12.89] & {$[8.861]$} & [14.35] & {$[5.652]$} & [4.692] & [7.076] & [3.807] & {$[4.273]$} \\
\hline \multirow{3}{*}{$\begin{array}{c}\text { Exchange rate } \\
\text { changes }\end{array}$} & $p_{1}$ & 4.239 & -0.921 & $4.656 \#$ & $3.563 *$ & 1.447 & 0.210 & $1.026^{*}$ & 0.839 \\
\hline & & $(0.529)$ & $(0.366)$ & $(0.024)$ & $(0.003)$ & $(0.140)$ & $(0.884)$ & $(0.004)$ & $(0.186)$ \\
\hline & & [6.739] & {$[1.021]$} & [2.074] & [1.234] & [0.982] & [1.443] & [0.361] & {$[0.634]$} \\
\hline \multirow[t]{4}{*}{ Trade to GDP ratio } & $p_{2}$ & $0.973 \#$ & 0.084 & 0.982 & 0.132 & 0.215 & 0.291 & 0.063 & -0.207 \\
\hline & & $(0.021)$ & $(0.937)$ & $(0.136)$ & $(0.840)$ & $(0.655)$ & $(0.277)$ & $(0.880)$ & $(0.586)$ \\
\hline & & {$[0.432]$} & {$[1.083]$} & {$[0.659]$} & {$[0.655]$} & {$[0.482]$} & {$[0.268]$} & {$[0.420]$} & {$[0.362]$} \\
\hline & \multicolumn{9}{|c|}{ US conditional Volatility spillover } \\
\hline \multirow[t]{3}{*}{ Constant } & $w_{0}$ & 2.094 & -0.951 & 3.781 & 1.180 & 3.783 & $-6.278^{\wedge}$ & 1.239 & $-8.485 \#$ \\
\hline & & $(0.456)$ & $(0.846)$ & $(0.384)$ & $(0.813)$ & $(0.233)$ & $(0.064)$ & $(0.648)$ & $(0.029)$ \\
\hline & & [8.810] & [4.910] & [4.351] & [5.008] & [3.173] & [3.395] & [2.721] & [3.897] \\
\hline \multirow{3}{*}{$\begin{array}{c}\text { Exchange rate } \\
\text { changes }\end{array}$} & $w_{1}$ & -0.659 & $-0.540^{\wedge}$ & -0.338 & 0.115 & $1.264^{\wedge}$ & $3.206^{*}$ & $1.735^{*}$ & $1.933^{*}$ \\
\hline & & $(0.180)$ & $(0.079)$ & $(0.514)$ & $(0.854)$ & $(0.067)$ & $(0.001)$ & $(0.000)$ & $(0.008)$ \\
\hline & & [0.492] & {$[0.308]$} & [0.519] & {$[0.630]$} & [0.690] & [1.001] & [0.377] & {$[0.736]$} \\
\hline \multirow[t]{3}{*}{ Trade to GDP ratio } & $w_{2}$ & 0.067 & -0.256 & 0.165 & 0.101 & $0.539^{\wedge}$ & $0.424 *$ & 0.161 & $-0.426^{\wedge}$ \\
\hline & & $(0.787)$ & $(0.565)$ & $(0.636)$ & $(0.827)$ & $(0.076)$ & $(0.000)$ & $(0.537)$ & $(0.060)$ \\
\hline & & {$[0.250]$} & {$[0.446]$} & {$[0.350]$} & [0.462] & [0.304] & {$[0.124]$} & [0.261] & {$[0.225]$} \\
\hline
\end{tabular}




\begin{tabular}{ccccccccccc} 
& \multicolumn{10}{c}{ EU conditional Volatility spillover } \\
Constant & $q_{0}$ & -6.200 & -6.962 & -13.691 & $-3.805 \#$ & -2.621 & $4.682^{*}$ & -0.817 & -1.010 \\
& & $(0.389)$ & $(0.131)$ & $(0.123)$ & $(0.021)$ & $(0.311)$ & $(0.002)$ & $(0.733)$ & $(0.674)$ \\
& & {$[7.205]$} & {$[4.612]$} & {$[8.889]$} & {$[3.099]$} & {$[2.590]$} & {$[4.357]$} & {$[2.405]$} & {$[2.409]$} \\
Exchange Rate & $q_{1}$ & 2.696 & $1.122 \#$ & 1.319 & $1.316 \#$ & 0.178 & -1.060 & $-0.407 \#$ & -0.172 \\
Changes & & $(0.479)$ & $(0.046)$ & $(0.341)$ & $(0.043)$ & $(0.747)$ & $(0.239)$ & $(0.045)$ & $(0.656)$ \\
& & {$[3.809]$} & {$[0.563]$} & {$[1.385]$} & {$[0.651]$} & {$[0.555]$} & {$[0.902]$} & {$[0.202]$} & {$[0.388]$} \\
Trade to GDP ratio & $q_{2}$ & -0.104 & 0.401 & $-0.800 \#$ & -0.231 & -0.319 & 0.112 & -0.114 & -0.153 \\
& & $(0.627)$ & $(0.483)$ & $(0.020)$ & $(0.510)$ & $(0.228)$ & $(0.476)$ & $(0.633)$ & $(0.442)$ \\
& {$[0.215]$} & {$[0.572]$} & {$[0.346]$} & {$[0.351]$} & {$[0.265]$} & {$[0.158]$} & {$[0.263]$} & {$[0.199]$} \\
\hline
\end{tabular}

Note: $P$ values and std. errors are in the parentheses and brackets, whilst ${ }^{*}, \#$, and ${ }^{\wedge}$ represent significance level at $1 \%, 5 \%$ and $10 \%$, respectively.

Finally, none of the time varying spillover models can be explained by exchange rate changes and total trade to GDP ratio in the case of the Ukraine. The insignificant evidences for the Ukraine draws attention to exploration of other macroeconomic or financial data to further empirically investigate conditional spillover effects.

The overall overview is that instrumental variables, namely exchange rate changes and Trade/GDP ratios, do not properly introduce clear cut results for all the countries to explain conditional spillover models. It should be noted, however, that among the obtained empirical results for instrumental intensities, exchange rate changes seem to me more powerful instrument in explaining the US and EU spillover parameters rather than trade/GDP ratio.

Finally, in order to fully evaluate the conditional model, variance ratios are also computed. The Table 9 shows that similar to constant model volatility spillover effects local shocks account for most of the market shocks on total variance, and the US variance ratios are still substantial compared to the EU and oil ratios.

Table 9: Summary statistics forVariance ratios for conditional spillover mode over the entire period, (from Sep 2000 to March 2012)

\begin{tabular}{cccccccccc}
\hline & & CRO & CZE & HUN & POL & ROM & RUS & TUR & UKR \\
\hline \multirow{2}{*}{ VR EU } & Mean & 21.117 & 24.469 & 23.240 & 20.168 & 16.716 & 9.456 & 12.122 & 8.553 \\
& Std.dev & 0.249 & 0.266 & 0.256 & 0.232 & 0.214 & 0.143 & 0.182 & 0.160 \\
\multirow{2}{*}{ VR US } & Mean & 16.118 & 26.541 & 24.913 & 27.777 & 17.745 & 21.047 & 25.102 & 10.136 \\
& Std.dev & 0.205 & 0.252 & 0.257 & 0.275 & 0.207 & 0.239 & 0.279 & 0.182 \\
VR OIL & Mean & 8.458 & 8.183 & 7.137 & 7.967 & 9.154 & 17.169 & 6.142 & 2.076 \\
& Std.dev & 0.149 & 0.140 & 0.116 & 0.124 & 0.157 & 0.218 & 0.118 & 0.065 \\
\multirow{2}{*}{ VR OWN } & Mean & 54.246 & 40.665 & 44.708 & 44.093 & 56.383 & 52.035 & 56.633 & 79.230 \\
& Std.dev & 0.345 & 0.319 & 0.322 & 0.322 & 0.335 & 0.335 & 0.242 & 0.286 \\
\hline
\end{tabular}


Similar to constant spillover model, the volatility spillovers effects from the US market shocks account for the most of the variances compared to regional EU stock market and oil market in conditional model. In contrast to constant spillover model, the regional and global volatility spillovers are almost equally distributed for the Czech Republic, Hungary, Romania, Poland, and the Ukraine. Eventually, own shocks appeared greatly in the case of the Ukraine which was then followed by Turkey and Croatia.

\subsection{AR (1)-GJR-GARCH $(1,1)$ dummy model: EU enlargement effect}

By using the equation (24) given by GARCH model, the effect of EU accession is empirically examined for EU member countries, namely for the Czech Republic, Hungary, Poland and Romania. Table 10 shows that significant results are obtained only in the case of Romania upon admission of the country into EU.

Table 10: Dummy variable model estimation results ${ }^{11}$

\begin{tabular}{|c|c|c|c|c|}
\hline & Czech & Hungary & Poland & Romania \\
\hline \multirow[t]{3}{*}{$\overline{c_{0}}$} & $0.583 *$ & $0.591 \#$ & 0.147 & $0.629 *$ \\
\hline & $(0.000)$ & $(0.013)$ & $(0.497)$ & $(0.001)$ \\
\hline & {$[0.174]$} & {$[0.238]$} & {$[0.217]$} & {$[0.202]$} \\
\hline \multirow[t]{3}{*}{$c_{1}$} & $-0.073^{\wedge}$ & -0.064 & $-0.106 \#$ & -0.031 \\
\hline & $(0.085)$ & (0.139) & $(0.021)$ & $(0.466)$ \\
\hline & [0.042] & [0.043] & {$[0.043]$} & [0.043] \\
\hline \multirow[t]{3}{*}{$\delta$} & -0.032 & 0.121 & -0.029 & $0.184 \#$ \\
\hline & $(0.642)$ & $(0.127)$ & $(0.714)$ & $(0.047)$ \\
\hline & {$[0.070]$} & {$[0.079]$} & {$[0.081]$} & [0.093] \\
\hline \multirow{3}{*}{$\gamma$} & $0.173 \#$ & 0.083 & $-0.235^{*}$ & -0.110 \\
\hline & $(0.012)$ & $(0.293)$ & $(0.005)$ & $(0.276)$ \\
\hline & [0.069] & {$[0.078]$} & {$[0.085]$} & [0.101] \\
\hline \multirow[t]{3}{*}{$\vartheta$} & $0.057 \#$ & $0.050^{\wedge}$ & 0.072 & 0.082\# \\
\hline & $(0.017)$ & $(0.079)$ & $(0.009)$ & $(0.010)$ \\
\hline & [0.023] & [0.028] & {$[0.028]$} & {$[0.031]$} \\
\hline \multirow[t]{3}{*}{$\Phi$} & $1.083 *$ & $1.240 *$ & $1.205^{*}$ & $0.903 *$ \\
\hline & $(0.000)$ & $(0.000)$ & $(0.000)$ & $(0.000)$ \\
\hline & {$[0.057]$} & {$[0.067]$} & {$[0.071]$} & [0.077] \\
\hline \multirow[t]{3}{*}{$\Phi_{\text {Dum }}$} & -0.328 & -0.455 & 0.078 & $-0.555 \#$ \\
\hline & (0.119) & $(0.112)$ & $(0.753)$ & $(0.050)$ \\
\hline & [0.210] & [0.286] & {$[0.250]$} & [0.286] \\
\hline \multirow[t]{3}{*}{$\theta$} & $0.774 *$ & $0.871^{*}$ & $0.979 *$ & $0.608 *$ \\
\hline & $(0.000)$ & $(0.000)$ & $(0.000)$ & $(0.000)$ \\
\hline & {$[0.035]$} & [0.039] & {$[0.041]$} & {$[0.056]$} \\
\hline \multirow[t]{3}{*}{$\varphi$} & $0.182 *$ & $0.206^{*}$ & $0.231 *$ & $0.228 *$ \\
\hline & $(0.000)$ & $(0.000)$ & $(0.000)$ & $(0.000)$ \\
\hline & {$[0.023]$} & {$[0.031]$} & {$[0.027]$} & {$[0.034]$} \\
\hline
\end{tabular}

${ }^{11}$ The Table 16 presents results only for mean equation in GJR-GARCH model. 
Note: PP values and std. errors are in the parentheses and brackets, whilst $*, \#$, and ${ }^{\wedge}$ represent significance level at 1\%, 5\% and 10\%, respectively.

More specifically, the findings indicate that the admission of Romania in EU in 2007 seems to be statistically significant, still with a negative coefficient of -0.555 . In other words, in the case of Romania volatility spillovers seem to decrease after the EU accession. However, the results of EU enlargement effect are significant in 2004. Additionally, quantified variance ratios for GARCH dummy model also revealed that the proportion of variance caused by regional EU effect is relevantly small for Romania, which is $9.3 \%$. Furhemore, quantified variance ratios for dummy Garch model is presented below in Table 11.

Table 11: Summary statistics for variance ratios for dummy variable model period from September 2000 to March 2012

\begin{tabular}{cccccc}
\hline & & CZE & HUN & POL & ROM \\
\hline VR EU & Mean & 18.566 & 15.005 & 23.105 & 9.335 \\
& Std. dev & 0.229 & 0.199 & 0.250 & 0.118 \\
VR US & Mean & 29.469 & 28.400 & 27.536 & 20.385 \\
& Std. dev & 0.272 & 0.235 & 0.275 & 0.246 \\
VR OIL & Mean & 9.221 & 8.593 & 7.593 & 11.492 \\
& Std. dev & 0.138 & 0.136 & 0.122 & 0.164 \\
VR OWN & Mean & 42.742 & 48.000 & 41.764 & 58.787 \\
& Std. dev & 0.316 & 0.332 & 0.318 & 0.317 \\
\hline
\end{tabular}

\section{Conclusion}

The paper studied the mean and volatility spillover effects from US, and EU stock markets, as well as from the oil market to eight individual European stock markets. Applying GJR-GARCH model, I found strong evidences of volatility transmission, particularly global, regional and world factors towards the national stock markets of eight European countries. The empirical outcomes also showed that amongst the three external factors, the US volatility spillover intensities account for most of the proportion of unexpected returns, except for Croatia and Romania, though. The empirical findings are also similar for pure global and regional stock markets while excluding the world factor oil. The empirical results of mean spillover effects are mixed and imply no strong evidences for Croatia, Hungary and Turkey. In addition to that, through various specifications in the so-called sensitivity analysis, I have revealed that the EU mean spillover effects are fairly sensitive in conjunction with the US mean spillover effects towards individual stock markets countries. Moreover, the results also showed that for no European Union member country is highly influenced by their own local shocks, which, however, appeared to be the highest in the Ukraine that was followed by Turkey and Croatia.

Furthermore, oil market shocks are found to be significant for all countries and, in particular, drive the stock returns of Russia with very high and positive coefficients. 25 
This finding is readily explained by a higher presence of oil and gas sector companies in the total market capitalization for Russian stock market. On the other hand, there are weak indications of asymmetric responses. More specifically, only Romania, Poland and the Ukraine asymmetrically responded to EU market shocks. Asymmetrical responses towards US shocks are found only in the case of Romania. Only the stock returns of Russia respond asymmetrically to oil price market shocks, though the response is fairly weak.

Additionally, in order to test the European Union enlargement effect through spillover effects on stock markets, I utilized the presence of a dummy variable constant model. I found out that the effect is evident only in the case of Romania. Thus, the overall inference of the dummy model is that EU membership matters for stock returns in Romania while being significant and still negative. Although the significance level is not statistically high, it can reflect some evidence of hypothesis on EU enlargement effect.

Finally, I also found statistically significant results for a conditional model and the conditional model appeared to be prior to the constant spillover model. Overall, the empirical outcomes of conditional spillover model can be summarized based on two essential inferences, the first of which is related to estimation results on parameters of global and regional markets. More specifically, empirical findings of exchange rate changes in most cases are highly significant and positive for US spillover effects, while when judged by sign and scale of coefficients for the EU spillover effects, the empirical results are found to be relatively weak or insignificant. The second implication is that most of the parameters both for mean and spillover effects are significantly explained by exchange rate changes rather than the total trade/GDP ratio, which shows the relative importance of exchange rate fluctuations for spillover effects amongst examined European countries.

\section{Reference}

BAELE, L. (2005). Volatility Spillover Effects in European Equity Markets, Journal of Financial and Quantitative Analysis 40(2), Pp. 373-401.

BEINE, J., CAPORALE, G.M., GHATTAS, M. S., SPAGNOLO, N. (2010). Global and regional spillovers in emerging stock markets: A multivariate GARCH-in-mean analysis. Emerging Markets Review, 11(2) Pp. 250-260.

BEKAERT, G., HARVEY, C.R. (1997). Emerging Equity Market Volatility, Journal of Financial Economics, 43(1), Pp. 29-77.

BOLLERSLEV, T. (1986). Generalized Autoregressive Conditional Heteroskedasticity, Journal of Econometrics 31(3), Pp. 307-327.

BROOKS, C., (2008). Introductory Econometrics for Finance, Cambridge, University press, Pp.170-174.

CHRISTIANSEN, C. (2004). Decomposing European Bond and Equity Volatility, Working paper, F -2004-01 Finance Research Group, Aarhus School of Business. 
GILMORE, C. G., LUCEY, B. M., MCMANUS, G. B., (2006). The dynamics of Central European equity market comovements" The Quarterly Review of Economics and Finance, vol.48 (1) Pp. 605-622. DOI:10.1016/j.qref.2006.06.005.

ENGLE, R. F. (1982). Autoregressive Conditional Heteroskedasticity with Estimates of the Variance of United Kingdom Inflation, Econometrica, vol. 50 (4), Pp., 987-1007.

ENGLE, R. F., NG, K.V. (1993). Measuring and testing the impact of news on volatility. The Journal of Finance, Vol.48, (5), pp. 1749-1778. DOI: 10.1111/j.15406261.1993.tb05127.x.

GOETZMANN, W., IBBOTSON, G.R. (2006). The equity risk premium: Essays and explorations. Oxford University Press, pp. 368-367.

HAMAO, Y., MASULIS, R., NG, K.V. (1990). Correlation in prices changes and volatility across international stock markets, The Review of Financial Studies 3(2) Pp. 281-307.

KASMAN, A., KASMAN, S., TORUN, E. (2009). Dual long memory property in returns and volatility: Evidence from the CEE countries' stock markets, Emerging Markets Review. 9(4) Pp.122-139. DOI: 10.1016/j.ememar.2009.02.002.

KOCENDA, E., HANOUSEK, J. (2010). Foreign News and Spillovers in Emerging European Stock Markets, William Davidson Institute Working Paper, 983.

GILMORE C.G., MCMANUS, M.G. (2002). International portfolio diversification: US and Central European equity markets, Emerging Markets Review.3(1), pp. 69-83. DOI: 10.1016/S1566-0141(01)00031-0.

ÉGERT, B., KOUBAA, Y. (2004). Modelling Stock Returns in the G-7 and in Selected CEE economies: A Non-linear GARCH Approach. William Davidson Institute Working Paper, No. 663.

DVORAK, T., PODPIERA, R. (2006). European Union Enlargement and Equity Markets in Accession Countries. Emerging Markets Review, Vol. 7 (2), Pp.129-146.

NG, A., (2000). Volatility Spillover Effects from Japan and the US to the Pacific-Basin. Journal of International Money and Finance, 19 (2) Pp. 207-233. DOI: 10.1016/S02615606(00)00006-1.

ROCKINGER, M., URGA, G. (2001). The evolution of stock markets in transition economies. The Journal of Business \& Economic Statistics, vol. 19, pp.73-84. DOI: 10.1006/jcec.2000.1669.

WALTER, E. (2010). Applied Econometric times Series. John Wiley \& Sons, Inc., pp.155-156. 


\section{Appendix}

Table A2: Wald test results in asymmetric model from September 2000 to March 2012

\begin{tabular}{ccccccc}
\hline & Wald $_{1}$ & Wald $_{2}$ & Wald $_{3}$ & Wald $_{4}$ & Wald $_{5}$ & Wald $_{6}$ \\
\hline CRO & $2.936^{\wedge}$ & 1.618 & 0.681 & 1.089 & 4.857 & 1.309 \\
& $(0.087)$ & $(0.203)$ & $(0.794)$ & $(0.297)$ & $(0.057)$ & $(0.252)$ \\
CZE & 0.023 & 1.175 & 0.108 & 1.402 & 0.065 & 0.377 \\
& $(0.878)$ & $(0.278)$ & $(0.741)$ & $(0.236)$ & $(0.798)$ & $(0.539)$ \\
HUN & 0.386 & 0.383 & 0.493 & $5.439 \#$ & 0.038 & 0.001 \\
& $(0.584)$ & $(0.536)$ & $(0.482)$ & $(0.020)$ & $(0.845)$ & $(0.986)$ \\
POL & 0.665 & 0.012 & 0.266 & $4.679 \#$ & 0.554 & 1.429 \\
& $(0.415)$ & $(0.910)$ & $(0.606)$ & $(0.030)$ & $(0.456)$ & $(0.232)$ \\
ROM & 1.318 & 0.002 & $3.120^{\wedge}$ & 2.204 & $7.358^{*}$ & 0.446 \\
& $(0.251)$ & $(0.962)$ & $(0.077)$ & $(0.138)$ & $(0.006)$ & $(0.504)$ \\
RUS & 0.318 & 0.057 & 0.001 & $3.741 \#$ & 0.001 & $5.561^{\wedge}$ \\
& $(0.572)$ & $(0.810)$ & $(0.991)$ & $(0.050)$ & $(0.981)$ & $(0.090)$ \\
TUR & 0.104 & 0.808 & 0.409 & 0.432 & 0.001 & 1.607 \\
& $(0.746)$ & $(0.369)$ & $(0.522)$ & $(0.511)$ & $(0.996)$ & $(0.205)$ \\
UKR & 1.701 & 0.402 & 2.515 & $17.300^{*}$ & 1.317 & 0.650 \\
& $(0.192)$ & $(0.526)$ & $(0.078)$ & $(0.000)$ & $(0.251)$ & $(0.420)$ \\
\end{tabular}

Note: $P$ values and std. errors are in the parentheses and brackets, whilst $*$,\#, and ${ }^{\wedge}$ represent significance level at 1\%, 5\% and 10\%, respectively, and also null hypotheses of joined Wald tests are presented below.

Table A3: Wald test results under oil exclusion constant spillover model (September 2000- March2012)

\begin{tabular}{ccccc}
\hline & Wald $_{1}$ & Wald $_{2}$ & Wald $_{3}$ & Wald $_{4}$ \\
\hline CRO & $52.562 *$ & 69.398 & 3.547 & 121.11 \\
& $(0.000)$ & $(0.000)$ & $(0.029)$ & $(0.000)$ \\
CZE & 206.07 & 190.57 & 7.259 & 379.82 \\
& $(0.000)$ & $(0.000)$ & $(0.002)$ & $(0.000)$ \\
HUN & 201.93 & 163.76 & 6.395 & 570.30 \\
& $(0.000)$ & $(0.000)$ & $(0.002)$ & $(0.000)$ \\
POL & 238.27 & 131.83 & 9.873 & 376.69 \\
& $(0.000)$ & $(0.000)$ & $(0.001)$ & $(0.000)$ \\
ROM & 61.385 & 87.802 & 4.851 & 171.67 \\
& $(0.000)$ & $(0.000)$ & $(0.009)$ & $(0.000)$ \\
RUS & 103.73 & 29.021 & 4.158 & 138.54 \\
& $(0.000)$ & $(0.000)$ & $(0.021)$ & $(0.000)$ \\
TUR & 74.022 & 39.093 & 2.236 & 108.87 \\
& $(0.000)$ & $(0.000)$ & $(0.108)$ & $(0.000)$ \\
UKR & 15.426 & 24.110 & 10.048 & 42.931 \\
& $(0.000)$ & $(0.000)$ & $(0.001)$ & $(0.000)$ \\
\hline
\end{tabular}


Note: $P$ values and std. errors are in the parentheses and brackets, whilst $*$,\#, and $\wedge^{\wedge}$ represent significance level at 1\%, 5\% and 10\%, respectively, and also null hypotheses of joined Wald tests are presented below:

$H_{0}^{1}: \gamma_{j}=\theta_{j}:$ no global US spillover effects

$H_{0}^{2}: \delta_{j}=\psi_{j}:$ no regional EU spillover effects

$H_{0}^{3}: \gamma_{j}=\delta_{j}:$ no mean spillover effects

$H_{0}^{4}: \theta_{j}=\psi_{j}:$ no asymmetric responses to US shocks 